\title{
Electrical Impedance Used for Measurement of Moisture Distribution in Thermal Insulation Plasters
}

\author{
Jitka Peterková1* ${ }^{\star}$ Martin Sedlmajer ${ }^{1}$, Magdaléna Michalčíková1, Jana Pařílková2 \\ ${ }^{1}$ Institute of Technology of Building Materials and Components, \\ Faculty of Civil Engineering, \\ Brno University of Technology, \\ Veveří 331/95, 60200 Brno, Czech Republic \\ 2 Institute of Water Structures, \\ Faculty of Civil Engineering, \\ Brno University of Technology, \\ Veveří 331/95, 60200 Brno, Czech Republic \\ *Corresponding author, e-mail: hroudova.j@fce.vutbr.cz
}

Received: 18 April 2017, Accepted: 08 March 2019, Published online: 09 April 2019

\begin{abstract}
High moisture in building materials has a negative influence on their physical and thermal insulating properties. When building materials incorporated in a structure exceed the maximum permissible moisture, the material could change its properties to such an extent that its next usage is unfeasible. In case of thermal insulating materials, it causes serious degradation of thermal insulating properties. During the development of advanced thermal insulation plasters, long-term laboratory experiments were performed using masonry construction fragments, which focused on the study of their moisture proportions. For this purpose a new non-destructive method of electrical impedance was used, which enables measurements on defined levels in a matrix of test samples. Results obtained by measurements made on the surface of the samples were compared with the results obtained by a capacitive hygrometer. It was concluded that these methods provided similar results. The least moisture sensitive was the mixture, which was applied on masonry pillar $E$. In comparison with used thermal insulation plasters commonly used today this plaster shows considerably lower value of mass moisture under laboratory conditions, 1.38\%. This pillar also exhibited the most uniform course of conductance measured along its height.
\end{abstract}

Keywords

electrical impedance, moisture, thermal insulation plaster, moisture probe

\section{Introduction}

The utilization of non-destructive electrical measuring methods for the testing of physical-chemical properties of materials is very common in civil engineering as well as other fields. The electrical properties of materials can be heavily influenced by moisture, whether the mass moisture of the material or relative air humidity. It is generally known that water is characteristic by its higher relative permittivity $\varepsilon_{\mathrm{r}}=80$. This high value of permittivity is caused by the properties of the water molecule $\mathrm{H}_{2} \mathrm{O}$ itself, when partial charges of oxygen and hydrogen enable good solubility of polar and ionic compounds in water.

Many research teams are examining material properties by electrical, electro-chemical, electro-physical, electro-mechanical, electro-magnetic and other methods, which enable the determination of moisture content or its transport. For example Chubinskii et al. [1] used (besides other methods) electrical measuring methods for the study of the structure of wood materials with different moisture. Fursa et al. [2, 3] presented articles aimed at non-destructive mechanical-electrical methods. His team presented in a research article [2] the results of an investigation in the determination of mechanical properties of concrete in dependence on temperature and moisture conditions. They also studied the influence of moisture on the parameters of the electrical signal. The aim of this study was creating an algorithm for the non-destructive electro-mechanical testing of heterogenous materials that contain piezoelectric inclusions under changes in their moistness [3]. 
Lebedev et al. [4] dealt with the heat and moisture transport in multiple-layer objects. A team of scientists from Riga Technical University, Faculty of Civil Engineering in Latvia used the electrical impedance spectrometry method - EIS for the detection of moisture distribution in autoclaved aerated concretes $[5,6]$. This method was also used by McCarter and Garvin for a study of the dependence of electrical impedance on moisture in cement materials [7].

Next instance of using this method, or rather its use in the field of building materials is the determination of impedance properties of self-compacting concrete (SCC) $[8,9]$. Results indicate, that EIS appears to be an interesting tool for describing the behaviour of concrete during hydration. A change in frequency characteristics confirms the assumptions that changes in the impedance loss coefficient occur with changes in physical properties. Differences in the loss coefficient spectrums show the most probable relax times, situated out of the frequency spectrum used. Next, a connection between porosity was confirmed, more precisely the determination of its rate during hydration in the air, with the dependence of the imaginary part of electrical impedance on the real part $[8,9]$.

Based on the accumulated knowledge and a literary survey, the EIS method was chosen for the study of moisture distribution in newly developed thermal insulation plasters, despite the method is usually used in the field of electrotechnology, medicine, archeology but also in the field of water management [8-17].

\section{Electrical impedance spectrometry}

The principle of EIS is the observation of frequency dependence of dielectric losses, the values of which can be several times higher in composite materials and plastics compared to most materials commonly used in civil engineering [8].

Electrical impedance, unlike electrical resistance, is a complex resistance that alternating electric current must negotiate in a porous environment. Next to resistance it involves reactance, i.e. the capacitive and induction effects of the environment (capacitance $X_{C}$ and inductance $X_{L}$ ). If electrical resistance $R$ of a resistor characterises the properties of porous environments in a direct-current circuit, electrical impedance $\boldsymbol{Z}$ characterises the properties of porous environments in alternating-current circuits. Contrary to electrical resistance where voltage is in phase with current, phases in the case of electrical impedance can be shifted according to the character of reactance.
Electrical impedance $\boldsymbol{Z}$ can be expressed as the Ohm's formula for alternating current circuits, i.e. a ratio of a voltage phasor $\boldsymbol{U}$ and current phasor $\boldsymbol{I}$.

$$
\boldsymbol{Z}=\frac{\boldsymbol{U}}{\boldsymbol{I}} .
$$

Much like in the case of resistance $R$ in direct-current circuits, the values of electrical impedance are expressed in ohms $[\Omega]$.

The frequency characteristics of electrical impedance $\boldsymbol{Z}$ can be expressed as a function of a complex variable in algebraic form

$\boldsymbol{Z}=R+j \cdot X$

where $R$ is resistance, constituting the real part of electrical impedance independent of frequency but directly dependent on water content (of the porous environment) and $X$ is reactance, which is the imaginary part of electrical impedance, it changes with frequency and is directly linked to the properties of the environment being examined (particle size distribution, porosity, etc.).

The impedance vector modulus $|Z|$ can be expressed by the Pythagorean Theorem as

$|Z|=\sqrt{R^{2}+X^{2}}$,

and the phase shift is expressed as

$\varphi=\operatorname{arctg}\left(\frac{X}{R}\right)$.

Electrical impedance $Z$ of a porous environment is therefore always equal or higher than real electrical resistance $R$ and is dependent on inductance (inductor reactance) $X_{L}=\omega L$ and capacitance (capacitor reactance) $X_{C}=$ $(\omega C)^{-1}$ of each component in the alternating current circuit determined at the frequency $f(\omega=2 \pi f)$.

Porous environments can be described by the electrical impedance of an equivalent electrical circuit incorporating a resistor, inductor and a capacitor. They can be wired either in series (all components of the circuit have the same current phasor) or as a parallel circuit (all components have the same voltage phasor), which, incidentally, appeared to be more suitable for application in the porous environment examined in this experiment.

The inverse value of the electrical impedance $\boldsymbol{Z}$ is the admittance $\boldsymbol{Y}[\mathrm{S}]$ which describes the apparent conductivity of the porous medium and the phase shift of the voltage upstream of the harmonic alternating current of the given frequency $f$. 
$\boldsymbol{Y}=\frac{1}{\boldsymbol{Z}}=\frac{1}{R+j X}=\frac{R}{R^{2}+X^{2}}+j \frac{-X}{R^{2}+X^{2}}=G+j B$,

where $B[\mathrm{~S}]$ susceptance (apparent conductivity) is the imaginary component of admittance.

$$
B=\operatorname{Im}(\boldsymbol{Y})=\frac{-X}{R^{2}+X^{2}}=\frac{-X}{|Z|^{2}} .
$$

Electrical conductance $G$ is inverse to electrical resistance $\mathrm{R}$ and its basic unit is the siemens [S]. Specific conductance, also known as conductivity $\sigma\left[\mathrm{S} \cdot \mathrm{m}^{-1}\right]$, quantifies the ability of an environment to conduct electric current. Conductivity is most commonly measured by opposing electrodes of a sensor placed in a porous environment with the area of $1 \mathrm{~cm}^{2}$. The result of this measurement is quantified in $\mathrm{S} \cdot \mathrm{m}^{-1}$.

$\sigma=\frac{1}{\rho}=\frac{l \cdot G}{A}$

where $\rho[\Omega \cdot \mathrm{m}]$ is the electrical resistance (resistivity), which express value of electrical resistance of the conductor with a unit cross-section per unit length, $l[\mathrm{~m}]$ is the distance between the electrodes and $A\left[\mathrm{~m}^{2}\right]$ is the perpendicular cross-sectional area of the electric conductor formed by the porous environments under investigation.

Conductivity is most commonly measured by opposing electrodes of a sensor placed in a porous environment with the area of $1 \mathrm{~cm}^{2}$. The result of this measurement is quantified in $\mathrm{S} \cdot \mathrm{m}^{-1}$.

The moisture profile of the masonry pillars covered in the newly developed plasters was measured using a $Z$-meter IV [18], see Fig. 1, which allows to perform a frequency analysis of the porous environment in the range $100 \mathrm{~Hz}$ to $200 \mathrm{kHz}$. Measurement of pillars loaded with permanent moisture and relative humidity was performed at frequency $f=8 \mathrm{kHz}$.

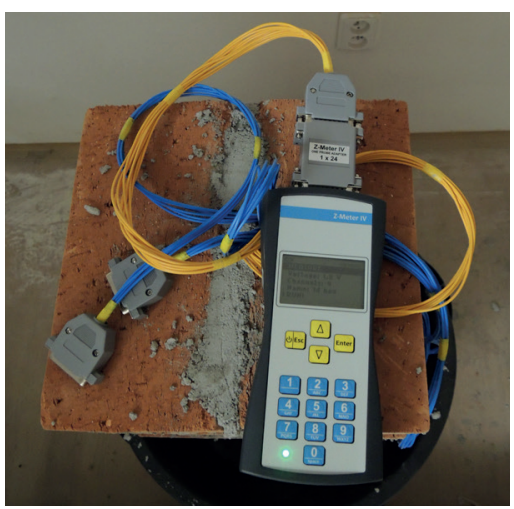

Fig. 1 Z-meter IV

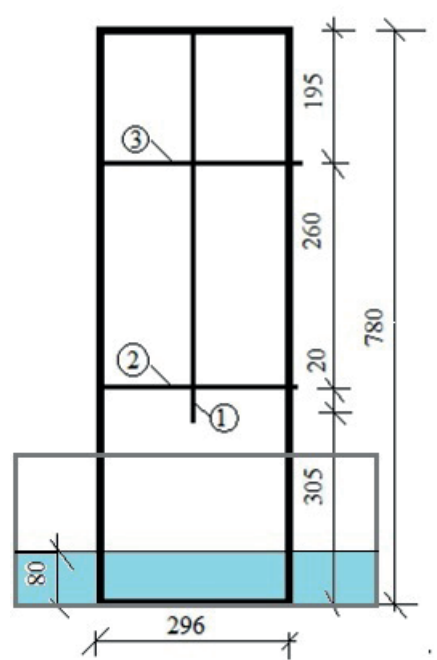

Fig. 2 Schematic drawing of a masonry pillar with the EIS probes installed, positioned in a plastic circular tub with a permanent water level (1-vertical, long probes; 2, 3-horizontal, short probes)

3 Study of the moisture profile of masonry pillars by EIS The development of the thermal insulation plasters involved the examination of their hygrothermal behaviour. Apart from conventional methods for determining the hygroscopic properties of hardened mortars (hygroscopic sorption properties according to EN ISO 12571, capillary absorption coefficient according to EN 1015-18, water vapour permeability according to EN 1015-18), the measurements focused on the moisture profile of the plasters applied on masonry pillars exposed to permanent moisture. The measurements were made using EIS, where the measurements were carried out in an alternating electric field of harmonic flow.

A total of 5 masonry pillars were constructed from solid clay bricks with EIS probes embedded inside. The pillars were placed in round tubs with the diameter of $550 \mathrm{~mm}$. Fig. 2 shows a diagram of a pillar with probe positions. Moisture transport was studied using two types of EIS probes with a varied number of electrodes to suit the profile being measured. There were short EIS probes which had $290 \mathrm{~mm}$ in length and were fitted with 6 sensor electrodes and long probes measuring at $475 \mathrm{~mm}$ and consisting of 10 electrodes. The short probes were installed in the pillars in the middle of their horizontal profiles at the height of 325 $\mathrm{mm}$ and $585 \mathrm{~mm}$ from the bottom of the pillar so that the first and last electrode on the probe would face the edge of the raw post, see Fig. 2. The long probes were placed vertically down the centre of the pillars at the height of $305 \mathrm{~mm}$ from the bottom, see Fig. 2. Horizontal probes 2 and 3 were placed in levels where different moistures were expected in the monitored environment. Trends measured at $325 \mathrm{~mm}$ 
are influenced by rising water, the environment at $585 \mathrm{~mm}$ can be considered air-dry. Vertical probes located in the axis of the pillars track environmental changes in height. The measuring sensor consists of two types of electrodes, represented by stainless steel tubes of $12 \mathrm{~mm}$ in diameter, lengths of $25 \mathrm{~mm}$, each with insulated spacing polyamide tubes of the same diameter. It is possible to assume the spherical theoretical distribution of AC-current lines in pillars during EIS measurements. Fig. 3 shows the probes (moisture sensor rods) used in this experiment. Once constructed and with the probes embedded, the pillars were covered in the experimental lightweight thermal insulation plasters at a layer of $20 \mathrm{~mm}$. The plasters were designed for interiors with high relative humidity. The pillars and plasters respectively were marked A through E. Pillar A was coated in the reference plaster, which was a thermal insulation plaster available on the EU market. Its purpose of this was to provide comparison for the hygrothermal behaviour of the advanced experimental thermal insulation plasters (these plasters are silica-based and were developed as part of project 14-31282P - "Theoretical and experimental analysis of the hygrothermal stress on the behavior of thermal insulation materials and rehabilitation materials" funded by the Grant Agency of the Czech Republic). After the plasters had matured, the pillars were subjected to moisture stress in the form of liquid water, which was poured in the tubs and kept at a constant level of $80 \mathrm{~mm}$. Environmental laboratory conditions (temperature and relative humidity) were being monitored throughout the measurements. A level of elevated humidity was kept in the laboratory on purpose. Table 1 lists the pillars and plasters including the plaster composition. The measurement was conceived as relative, the measured parameters of the EIS method are evaluated on the masonry pillars B to E in relation to the reference pillar A. Fig. 4 shows the tested pillars coated in the experimental plasters.

\section{Evaluation of measurements}

The EIS measurement of moisture transport inside each masonry pillar was commenced immediately after the pillars were constructed and continued in regular weekly intervals. The moisture transport in the pillars had eventually stabilised and, given the changes in moisture, the behaviour of the pillars with the plasters applied was observed over an extended period of time. The interior temperature was kept within $18.9{ }^{\circ} \mathrm{C}$ and $20.4{ }^{\circ} \mathrm{C}$ for the entire time of measurement. Relative indoor humidity ranged from $60.8 \%$ to $80.6 \%$. The relative humidity in
Table 1 Overview of the masonry pillars with thermal insulation plasters applied

\begin{tabular}{lc}
\hline Pillar & Type of plaster \\
\hline A & Reference plaster based on silicates \\
& Experimental plaster (lightweight aggregate (LA) - type A \\
B & -3 fractions, type B -1 fraction, limestone, CEM I 42.5R, \\
& lime hydrate, metakaolin, chemical agents) \\
& Experimental plaster (LA - type A - 3 fractions, type \\
C & B - 1 fraction, limestone, CEM I 52.5R, lime hydrate, \\
& metakaolin (2x the amount than in B, chemical agents + \\
& hydrophobisation agents)
\end{tabular}

Experimental plaster (LA - type A - 3 fractions, type B - 1 fraction, limestone, CEM I 52.5R, lime hydrate, metakaolin, fly ash, chemical agents + hydrophobisation agents, waste cellulose fibres - type A)

Experimental plaster (LA - type A - 3 fractions, type $\mathrm{B}-1$ fraction, type $\mathrm{C}-1$ fraction, limestone, CEM I

E $52.5 \mathrm{R}$, lime hydrate, metakaolin, fly ash, chemical agents + hydrophobisation agents, waste cellulose fibres - type B)
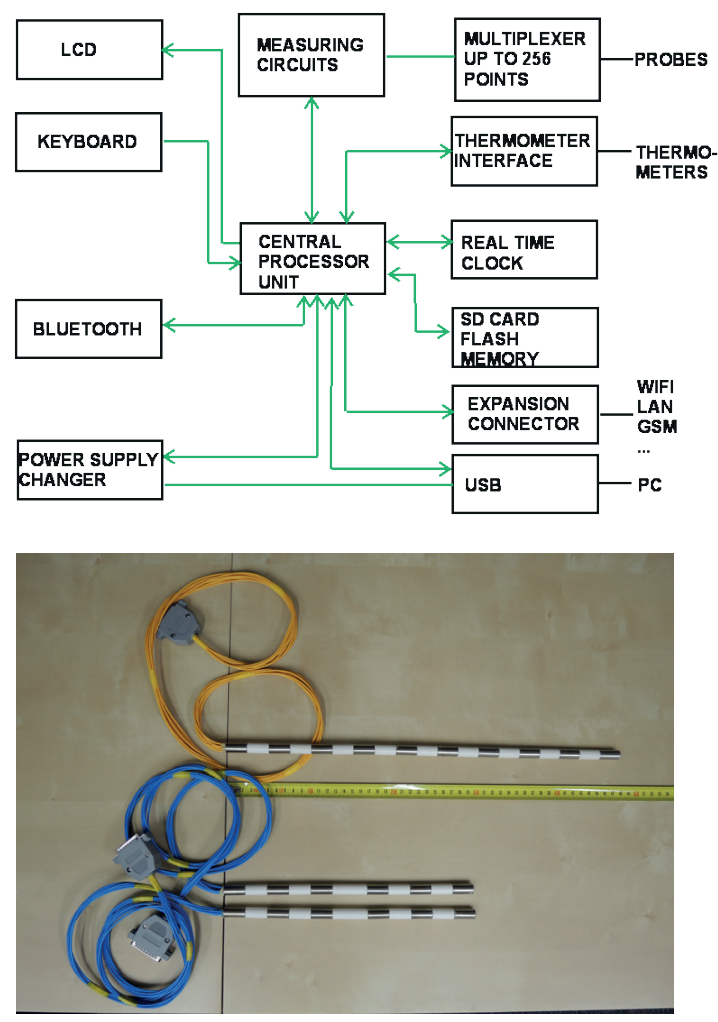

Fig. 3 Block diagram of measurement (above); Measuring EIS probes (below)

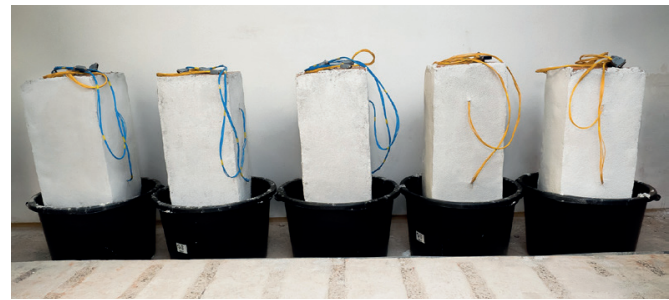

Fig. 4 Set of 5 masonry pillars with the mortars applied and probe wiring for measurement by the EIS method 
the testing space was especially high during rainy weather. Throughout measurement, a window was left open in the testing room for ventilation. It should be noted that the first three pillars (A, B and C) were built towards the end of 2015 and the EIS measurements were started on $7^{\text {th }}$ December 2015, i.e. on the day of construction. The pillars were plastered on $9^{\text {th }}$ December 2015 and on $6^{\text {th }}$ January 2016 were subjected to permanent moisture load by water reaching up to $80 \mathrm{~mm}$ from the bottom edge. Pillars D and E were constructed on $22^{\text {nd }}$ April 2016, their plasters were applied on $4^{\text {th }}$ May 2016 and the moisture load was introduced on $3^{\text {rd }}$ of June 2016. After the plasters had hardened, moisture was measured in selected places using a GMK 100 capacitive hygrometer. Moisture transport in the pillars was documented by the EIS method as a progression of conductance $G$ and admittance $Y$.

Fig. 5 and Fig. 6 show the progress of conductance $G$ along the height of the pillars. It holds that the higher the value of conductance, the higher the moisture content of the material. The scale of the $\mathrm{h}$ axis $[\mathrm{mm}]$ corresponds to the placement of the long probe, which was positioned vertically down the centre of each pillar. An evaluation of the measured progress of $G$ shows that the most stable moisture progress took place in pillar $\mathrm{E}$. The data show that the first set of pillars (A, B and C) reaches the highest values of $G$, which were recorded in one month after moisture stress was introduced. After this point, the pillars slowly dried until moisture transport had stabilised. Pillars D and E initially showed much higher values of $G$. After that, moisture transport began to stabilise and $G$ values started to decrease. No particularly significant changes in case of the moisture load were recorded, which was likely caused by the materials used, seeing as they contained oleate and stearate-based hydrophobic agents. The long probes document primarily the moisture transport through the masonry mortar and the bricks of the pillars because the effect of the dissipation layer created by the plaster composition and designed mainly to counter air humidity can be considered negligible in the centre of the pillars.

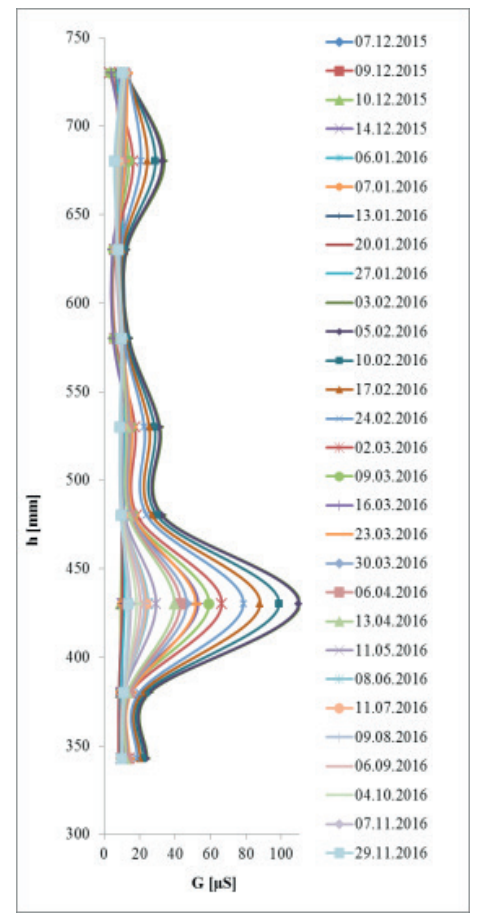

(a)

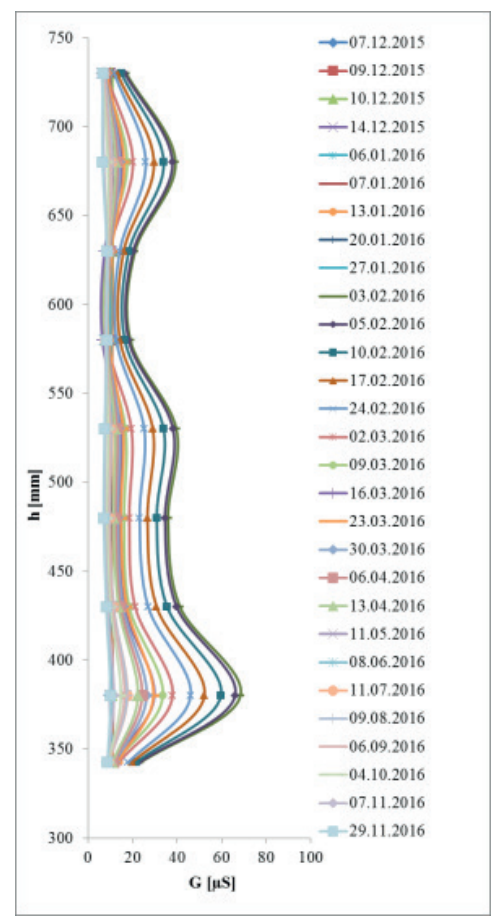

(b)

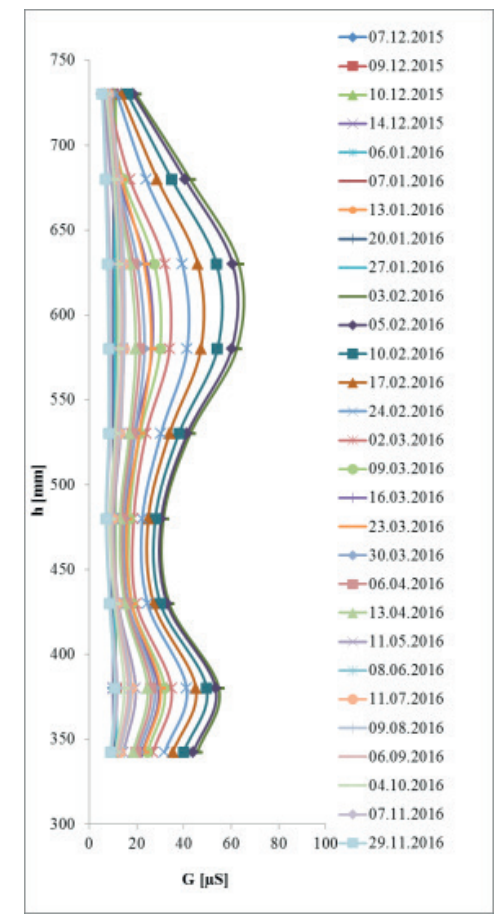

(c)

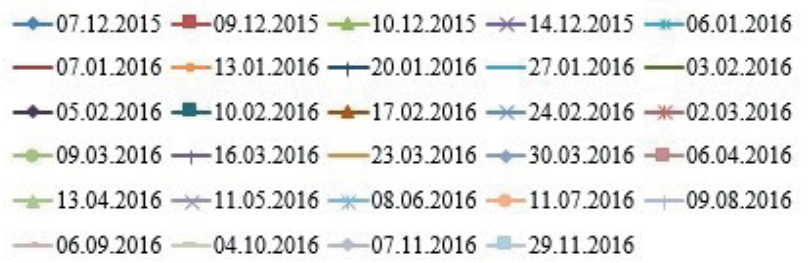

Fig. 5 Progress of conductance in pillar in the vertical direction, measured at the given time a) Pillar A; b) Pillar B; c) Pillar C 


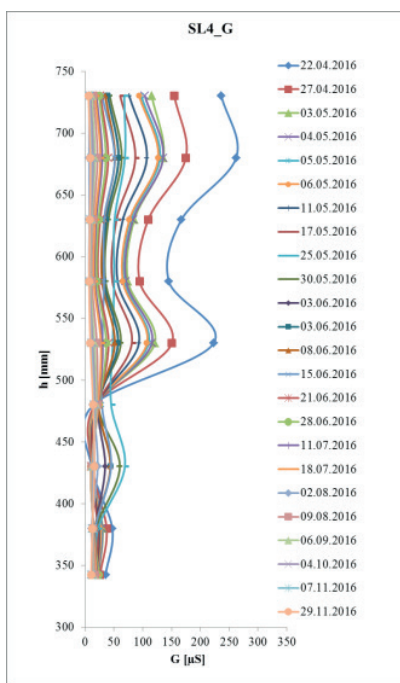

(a)

\begin{tabular}{|c|c|c|c|}
\hline 016 & $=-27.04 .2016$ & $=03$. & $*$ \\
\hline 016 & -06 & 2016 & -1 \\
\hline 16 & -30.05 .2016 & $\rightarrow 03.06 .2016$ & $=03.06 .2016$ \\
\hline-08 & -15.06 .2016 & -21.06 .2016 & -28.06 .2016 \\
\hline-11 & -18. & $\rightarrow 02.08$ & $=09.08$ \\
\hline & $一 04.10 .2016$ & $\because 07.11 .2016$ & $\rightarrow-29.11 .2016$ \\
\hline
\end{tabular}

Fig. 6 Progress of conductance in pillar in the vertical direction, measured at the given time a) Pillar D; b) Pillar E
On the other hand, the progress of $G$ measured by the short probes (Figs. 7-10) measured the performance of the plasters. Their sensor electrodes were positioned at the plaster-masonry interface. Furthermore, the position of the short probes in two positions was to determine changes in moisture in the proximity of the source of moisture and at a distance further away from it. Fig. 7 and Fig. 8 show the progress of $G$ in the horizontal position at the height of 325 $\mathrm{mm}$ from the bottom, Fig. 9 and Fig. 10 follow the progress of $G$ in the horizontal position at the height of $585 \mathrm{~mm}$ from the bottom. All the masonry pillars show higher values of $G$ in the centre of masonry mainly in the position of the lower probes, which was caused by the dominance of moisture transport through mortar. A similar trend can be seen here as in the case of the long probes, where the maximum values of conductance in the first set of pillars $(\mathrm{A}-\mathrm{C})$ are reached in one month after flooding, whereas in the case of the second set (D-E) it is immediately upon the commencement of measurement. The process of attaining equilibrium moisture content is again well documented as is the subsequent process of drying. The second set of pillars (D and E) showed low values of $G$ measured on opposite sides, which corresponds with their plaster composition.

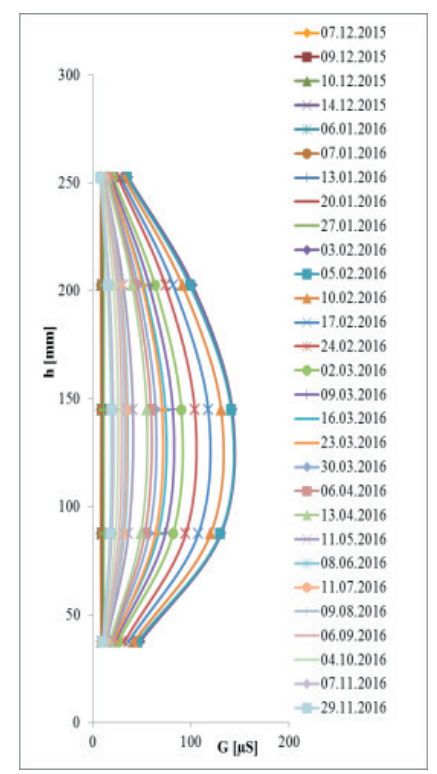

(a)

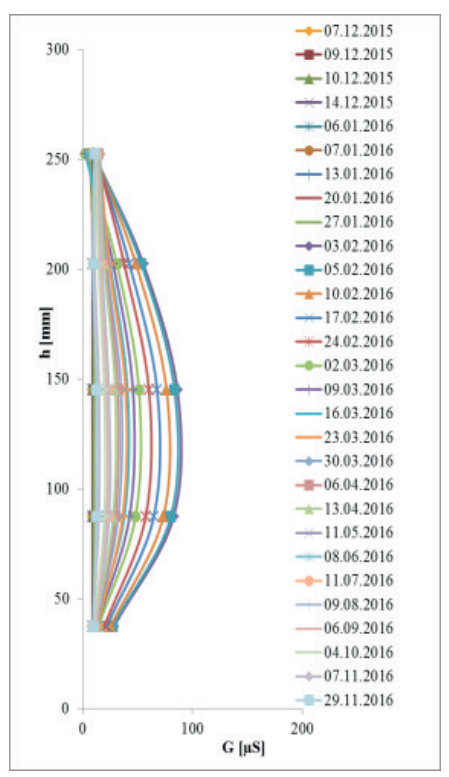

(b)

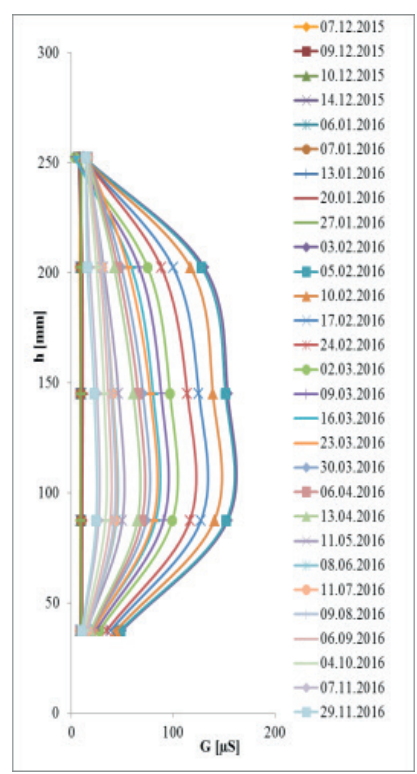

(c)

$$
\begin{aligned}
& \rightarrow-07.12 .2015-09.12 .2015 \leadsto-10.12 .2015 * 14.12 .2015 \rightarrow 06.01 .2016 \\
& \text { —07.01.2016 } \rightarrow-13.01 .2016+20.01 .2016-27.01 .2016-03.02 .2016 \\
& \rightarrow-05.02 .2016-10.02 .2016 \nrightarrow-17.02 .2016 \div 24.02 .2016 * 02.03 .2016 \\
& \rightarrow-09.03 .2016+16.03 .2016-23.03 .2016 \rightarrow 30.03 .2016 \rightarrow-06.04 .2016 \\
& \mp 13.04 .2016 \div 11.05 .2016 \div 08.06 .2016 \rightarrow-11.07 .2016+09.08 .2016 \\
& -06.09 .2016-04.10 .2016 \rightarrow 07.11 .2016-29.11 .2016
\end{aligned}
$$

Fig. 7 Progress of conductance in pillar in the horizontal direction, measured at a position of $325 \mathrm{~mm}$ from the bottom edge of the pillar, at the given time a) Pillar A; b) Pillar B; c) Pillar C 


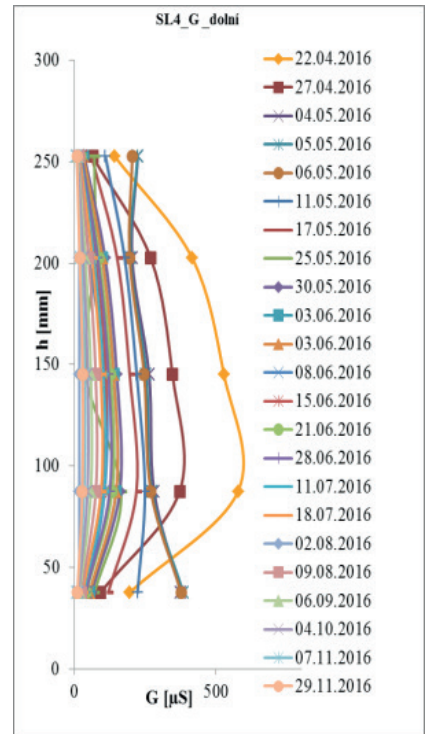

(a)
Fig. 8 Progress of conductance in pillar in the horizontal direction , measured at a position of $325 \mathrm{~mm}$ from the bottom edge of the pillar, at the given time a) Pillar D; b) Pillar E

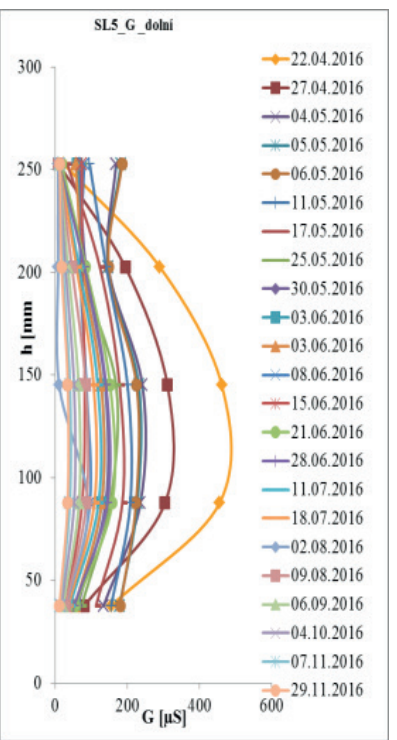

(b)

\begin{tabular}{|c|c|c|c|}
\hline-22.04 .2016 & $=-27.04 .2016$ & $\pitchfork-03.05 .2016$ & $\because 0$ \\
\hline-05.05 .2016 & -06.05 .2016 & -11.05 .2016 & -17.05 .2016 \\
\hline-25 & -30 & $\rightarrow 03$ & $=0$ \\
\hline-0 & $\div 15$ & -2 & -2 \\
\hline-1 & -18.07 .2016 & $\rightarrow 02.08 .2016$ & $-=09.08 .2016$ \\
\hline 920 & $一 04.10 .2016$ & $\because 07.11 .2016$ & $\Rightarrow-29.11 .2016$ \\
\hline
\end{tabular}

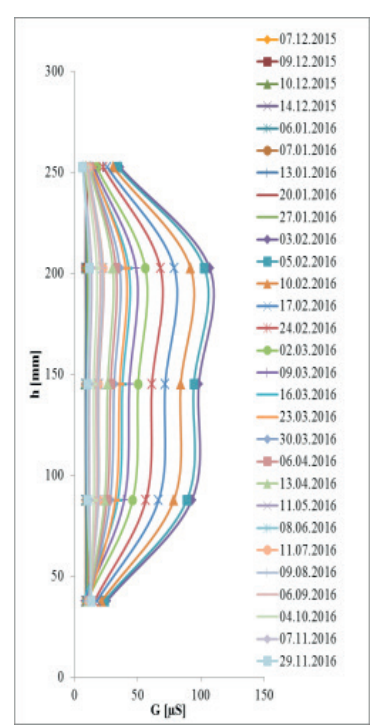

(a)

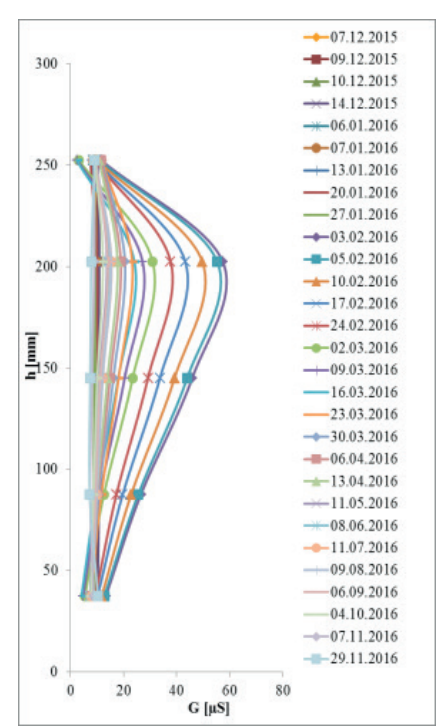

(b)
Figs. 11, 12 and 13 present the development of the values of average admittance $\bar{Y}$ in the individual measurement days. The values of $\bar{Y}$ for pillars A-C are shown on the main axis, values for pillars $\mathrm{D}$ and $\mathrm{E}$ are on the secondary axis. Admittance measurements in the Fig. 11 shows discontinuity which was caused by different properties of the developed plasters applied on the pillars.

It can be said that the drying of the pillars, as documented by the development of admittance, can be described by a third degree polynomial in all cases. In the case of the long probes, the following values of average admittance $\bar{Y}$ were recorded at time $t$ :

- pillar A: $\bar{Y}=-0.0024 \cdot t^{3}+0.1667 \cdot t^{2}-3.7918 \cdot t+36.988$

- pillar B: $\bar{Y}=-0.0031 \cdot t^{3}+0.21 \cdot t^{2}-4.5127 \cdot \mathrm{t}+39.266$

- pillar C: $\bar{Y}=-0.0039 \cdot t^{3}+0.2611 \cdot t^{2}-5.6297 \cdot \mathrm{t}+50.87$

- pillar D: $\bar{Y}=-0.0163 \cdot t^{3}+1.3755 \cdot t^{2}-40.626 \cdot \mathrm{t}+436.43$

- pillar E: $\bar{Y}=-0.0358 \cdot t^{3}+3.0085 \cdot t^{2}-87.095 \cdot \mathrm{t}+900.87$ In the case of the bottom short probes, the following values of average admittance $\bar{Y}$ were recorded at time $t$ :

- pillar A: $\bar{Y}=-0.0067 \cdot t^{3}+0.4588 \cdot t^{2}-10.617 \cdot t+107.09$

- pillar B: $\bar{Y}=-0.005 \cdot t^{3}+0.3247 \cdot t^{2}-6.8225 \cdot t+61.128$

- pillar C: $\bar{Y}=-0.0075 \cdot t^{3}+0.5155 \cdot t^{2}-11.695 \cdot t+116.15$

- pillar D: $\bar{Y}=-0.0087 \cdot t^{3}+1.2675 \cdot t^{2}-58.115 \cdot t+878.36$

- pillar E: $\bar{Y}=-0.0147 \cdot t^{3}+1.3344 \cdot t^{2}-46.661 \cdot t+646.89$ 


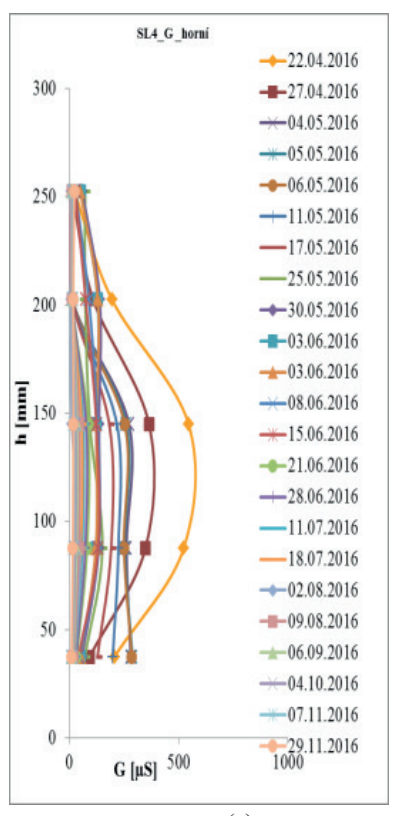

(a)

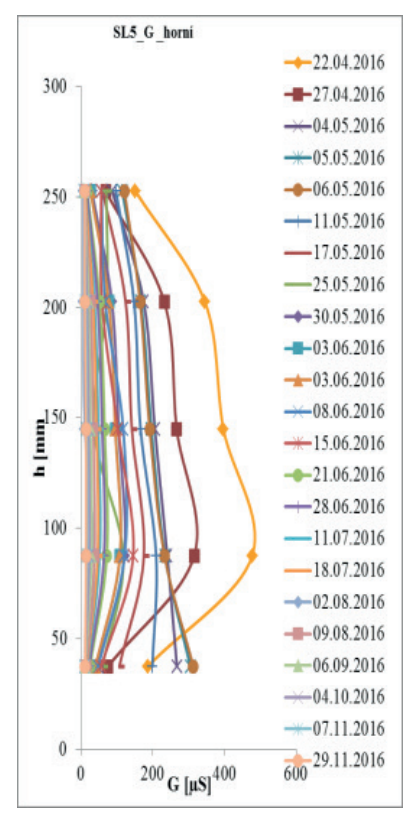

(b)
Fig. 10 Progress of conductance in pillar in the horizontal direction, measured at a position of $585 \mathrm{~mm}$ from the bottom edge of the pillar, at the given time a) Pillar D; b) Pillar E

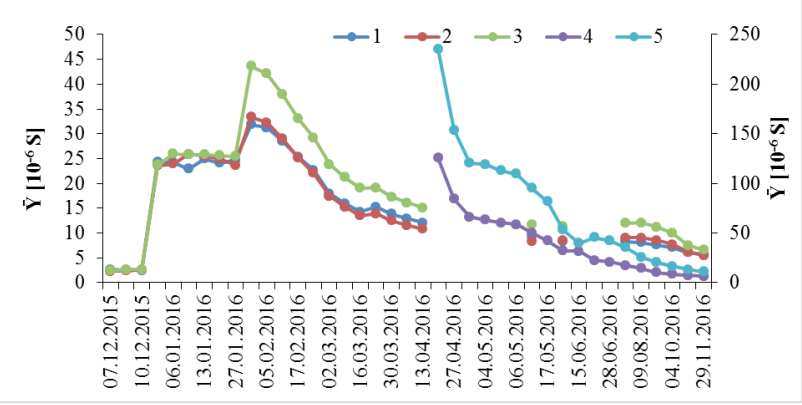

Fig. 11 Progress of admittance in pillars in the vertical direction measured at the given time

In the case of the upper short probes, the following values of average admittance $\bar{Y}$ were recorded at time $t$ :

- pillar A: $\bar{Y}=-0.0071 \cdot t^{3}+0.4782 \cdot t^{2}-10.269 \cdot t+84.364$

- pillar B: $\bar{Y}=-0.0032 \cdot t^{3}+0.2106 \cdot t^{2}-4.3092 \cdot t+35.685$

- pillar C: $\bar{Y}=-0.0052 \cdot t^{3}+0.3394 \cdot t^{2}-6.7614 \cdot t+50.704$

- pillar D: $\bar{Y}=-0.0152 \cdot t^{3}+1.5373 \cdot t^{2}-56.361 \cdot t+746.41$

- pillar E: $\bar{Y}=-0.0016 \cdot t^{3}+0.6556 \cdot t^{2}-39.764 \cdot t+668.08$

It should be noted that some readings pointed at a greater influence of elevated relative humidity on the overall moisture transport through the pillars. The EIS method documented the moisture transport through the pillars including moisture changes in the various types of plasters applied. The data shows that the plasters applied on pillars D and E saw lower values of conductance, which closely corresponded to the moisture values measured by the GMK 100 capacitive hygrometer, see the graph in Fig. 14.

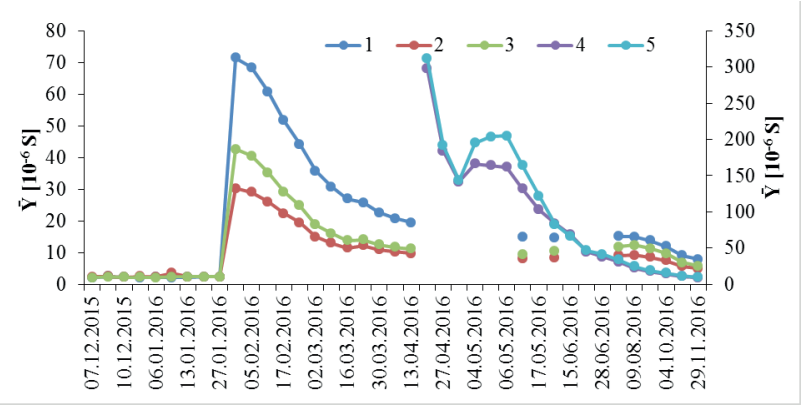

Fig. 12 Progress of admittance in the pillars in the horizontal direction at a height of $585 \mathrm{~mm}$ from the bottom edge, measured at a given time

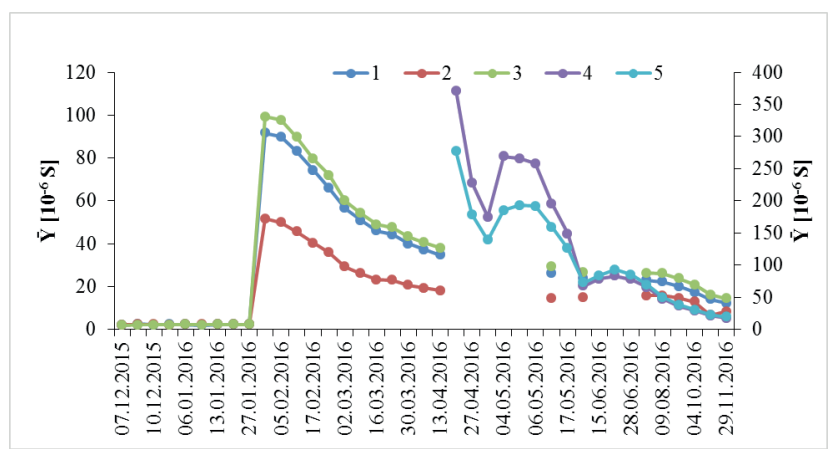

Fig. 13 Progress of admittance in the pillars in the horizontal direction at a height of $325 \mathrm{~mm}$ from the bottom edge, measured at the given time

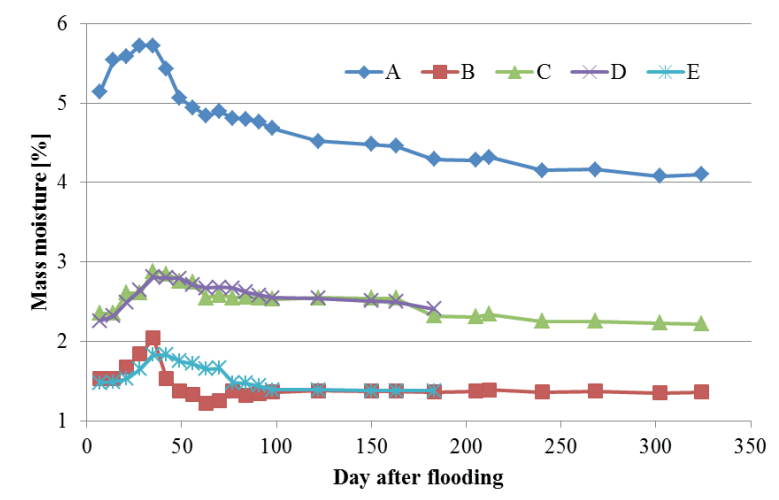

Fig. 14 Average values moisture per ass in \% for the entire time of measurement since flooding

The observation of moisture changes in one reference and four experimental thermal insulation plasters using a capacitive hygrometer began 7 days after flooding and was performed in 7-day intervals. It could be observed that 14 days after flooding, moisture gradually spread through the pillars, increasing the moisture content by mass (most noticeably in the bottom parts of the pillars). After 42 days of moisture loading, the pillars gradually started to dry. During the measurement it was possible to observe moisture fluctuations caused by increases in the relative humidity in the testing area. Furthermore, the plasters slowly dried until their moisture stabilised, which was recorded at 324 days after flooding in pillars A, B and C 
and in pillars $\mathrm{D}$ and $\mathrm{E}$ at 183 days since flooding. The high relative humidity in the testing room during rainy weather had a strong influence on the values of moisture content. The values of moisture content indicate that all the newly designed plasters have much higher moisture content (1.5 to 2 times higher) compared to the reference plaster. The lowest average moisture content was found in the plaster applied on pillar B. It can thus be said that the oleate and stearate-based hydrophobic agents which it contained proved efficient in terms of retarding moisture transport in the plasters.

A comparison of the results of both non-destructive moisture transport measurements indicates that the least moisture-sensitive plaster was the one applied on pillar E. Compared to thermal insulation plasters commonly used today, it shows a significantly lower material moisture content under laboratory conditions; $1.38 \%$. In addition, moisture development along the height of the specimen in the case of this plaster also corresponds to the most stable progress of conductance.

The evaluation of the obtained data and the conclusions was based on the evaluation of distribution of course of conductance in individual pillars B to E related to the courses measured in the reference pillar A and the correlation of the courses of admittance values determined by the outside probes of the horizontal probes with the course of the moisture values determined by the capacitive hygrometer at the corresponding levels. The statistical evaluation of the achieved results was not carried out due to the low number of experiments.

\section{References}

[1] Chubinskii, A. N., Tambi, A. A., Teppoev, A. V., Anan'eva, N. I., Semishkur, S. O., Bakhshieva, M. A. "Physical nondestructive methods for the testing and evaluation of the structure of woodbased materials", Russian Journal of Nondestructive Testing, 50(11), pp. 693-700, 2014.

https://doi.org/10.1134/S1061830914110023

[2] Fursa, T. V., Surzhikov, A. P., Osipov, K. Y. "A nondestructive mechanoelectrical method for determining the strength of concrete under variable temperature and humidity conditions", Russian Journal of Nondestructive Testing, 45(9), pp. 660-665, 2009.

https://doi.org/10.1134/S1061830909090101

[3] Fursa, T. V., Dann, D. D., Osipov, K. Y., Nesteruk, D. A. "The influence of humidity on the parameters of an electric signal under pulsed mechanical excitation of heterogeneous materials containing piezoelectric inclusions", Russian Journal of Nondestructive Testing, 47(6), pp. 404-411, 2011. https://doi.org/10.1134/S1061830911060064

\section{Conclusions}

Knowledge of the moisture content of building materials is an influential factor in assessing the thermal insulation effectiveness of materials. The assessment of the moisture development in these new thermal insulation plasters was somewhat non-traditionally made by means of electrical impedance spectrometry. This enabled a long-term observation of moisture changes in the masonry pillars which were coated in the newly developed thermal insulation plasters. Data collected during this measurement gave information about the moisture transport over time, after which it was possible to identify the mixture applied on pillar E as the least sensitive to moisture. The results of EIS measurements made only on the layers of plaster were correlated with moisture values determined by a capacitive hygrometer at specific positions on the pillars.

It can be concluded that the EIS method is useful as a supplementary method for documenting moisture transport through porous materials. It can be used with good results in the development of innovative building materials, as it can provide detailed information about areas with elevated moisture in the form of electrical quantities.

\section{Acknowledgement}

This paper was elaborated with the financial support of the projects GACR 14-31282P "Theoretical and experimental analysis of the hygrothermal stress on the behavior of thermal insulation materials and rehabilitation materials" and No. LO1408 "AdMaS UP - Advanced Materials, Structures and Technologies", supported by Ministry of Education, Youth and Sports under the "National Sustainability Programme I".

[4] Lebedev, O. V., Budadin, O. N., Slitkov, M. N., Avramenko, V. G., Kirzhanov, D. V. "Studying heat and moisture transfer phenomena during liquid-solid phase transitions in multilayer objects", Russian Journal of Nondestructive Testing, 42(10), pp. 700-708, 2006. https://doi.org/10.1134/S1061830906100093

[5] Rubene, S., Vilnitis, M. "Accuracy of humidity diostribution measurements in autoclaved aerated concrete constructions by electrical impedance spectrometry", In: 3rd Conference and Working Session within the frame of the International Program EUREKA, Brno, Czech Republic, 2015, pp. 156-164.

[6] Rubene, S., Vilnitis, M. "Methodology for detection of moisture distribution throughout the cross section of autoclaved aerated concrete masonry constructions by application of EIS method", In: 4th Conference and Working Session within the frame of the International Program EUREKA, Brno, Czech Republic, 2016, pp. 50-59.

[7] McCarter, W. J., Garvin, S. "Dependence of Electrical Impedance of Cement-Based Materials on their Moisture Condition", Journal of Physics D: Applied Physics, 22(11), pp. 1773-1776, 1989. https://doi.org/10.1088/0022-3727/22/11/033 
[8] Kusák, I., Luňák, M., Pazdera, L., Schauer, P. "Impedanční spektroskopie betonu s přechodovou vrstvou sodného vodního skla" (Impedance spectroscopy of concrete with a transition layer of sodium water glass), In: 38th International Conference and NDT Exibition, Defektoskopie 2008, Brno, Czech Republic, 2008, pp. 117-122, (in Czech) [online] Available at: https://www.ndt.net/article/defektoskopie2008/papers/117.pdf [Accessed: 04.04.2019]

[9] Kusák, I., Novák, P. "Impedanční spektroskopie samozhutnitelného betonu", (Tracking of Concrete by Means of Impedance Spectroscopy), presented at 12th International Scientific Conference, Brno, Czech Republic, April, 20-22, 2009, (in Czech). [online] Available at: https://www.fce.vutbr.cz/konferencefast/ukazka upravy_clanku.doc [Accessed: 05.04.2019]

[10] Barbiero, G., Miracapillo, C. "International application of EIS method (electrical impedance spectrometry) for soil humidity measuring, Results of Automated Bibliographical Search with ISI WEB of Knowledge", Consiglio Nazionale delle Ricerche, Roma, Italy, Rep. R/160, 2008.

[11] Breitkopf, C. "Impedance Spectroscopy, Old Technique - New Applications", presented at Lecture Series at Fritz-Haber-Institute Berlin "Modern Methods in Heterogeneous Catalysis", Berlin, Germany, Dec. 7, 2012.

[12] La Mantia, F., Vetter, J., Novák, P. "Impedance spectroscopy of porous materials: A general model of lithium-ion batteries", Electrochemica Acta, 53(12), pp. 4109-4121, 2008.

https://doi.org/10.1016/j.electacta.2007.12.060
[13] Pařílková, J., Zachoval, Z., Gardavská, Z., Fejfarová, M., Chromý, H. "Laboratorní stanovení hydraulické a elektrické vodivosti vzorků zemin" (Laboratory determination of hydraulic and electrical conductivity of soil samples), In: Hydrotechnics Symposium 2010, Prague, Czech Republic, 2010, pp. 90-107. (in Czech)

[14] Gu, P., Xie, P., Fu, Y., Beaudoin, J. J. "A.C impedance phenomena in hydrating cement systems: Frequency dispersion angle and pore size distribution", Cement and Concrete Research, 24(1), pp. 86-88, 1994.

https://doi.org/10.1016/0008-8846(94)90086-8

[15] Ayano, T., Wittmann, F. H. "Drying, moisture distribution, and shrinkage of cement-based materials", Materials and Structures, 35(3), pp. 134-140, 2002. https://doi.org/10.1007/BF02533581

[16] Gusmano, G., Bianco, A., Montesperelli, G., Traversa, E. "An EIS study of the humidity-sensitive electrical conduction of alkali-doped $\mathrm{TiO}_{2}$ films", Electrochemica Acta, 41(7-8), pp. 1359-1368, 1996. https://doi.org/10.1016/0013-4686(95)00457-2

[17] Esposito, V., de Florio, D. Z., Bertolo, J. M., Bearzotti, A., Falcaro, P., Innocenzi, P. "EIS study of humidity sensor based on meso-structured porous silica thin film material", In: Proceedings of the 204th Meeting of The Electrochemical Society, Orlando, Florida, USA, October, 12-16, 2003. Available at: http://orbit.dtu.dk/files/105813312/EIS_ study of humidity.pdf [Accessed: 04.04.2019]

[18] Pař́lková, J., Radkovský, K. "User's manual - Z-meter IV", Brno University of Technology, Brno, Czech Republic, pp. 1-19, 2016. 